\title{
Sexual Behavior in Modern Societies: An Interdisciplinary Analysis
}

\section{Bjørn Grinde ${ }^{1}[0$}

Accepted: 15 April 2021 / Published online: 28 April 2021

(c) The Author(s) 2021

\begin{abstract}
Humans, and other mammals, require specific interactions between two adults in order to procreate. The importance of these encounters for the genes has turned sex into an exceedingly varied and complicated form of behavior. Human sexual behavior is largely guided and motivated by feelings, and has a considerable impact on both individual well-being and the fabric of society. It is therefore important to assess how this aspect of life functions in industrialized societies. The present analysis uses the perspective of evolutionary biology but is based on research in sexuality, anthropology, animal behavior, positive psychology, and gender differences. Given that society should aim for maximizing the well-being of its members, the present situation does not appear to be optimal. The social environment of modern societies is likely to cause an increase in the prevalence of sex-related suffering and a reduction in the harvest of positive feelings. A relevant question is whether the situation regarding sex should be referred to as a 'disease of modernity.'
\end{abstract}

Keywords Sexuality $\cdot$ Diseases of modernity $\cdot$ Social structure $\cdot$ Feelings $\cdot$ Wellbeing $\cdot$ Quality of life

\section{Introduction}

We are born with innate tendencies of behavior to help us survive and reproduce. The behavioral functions of adults reflect a mix of nature and nurture; that is, genetic inheritance and environmental molding. If the environment differs from what the genes are tuned to, the result may be suboptimal. Sex is a key element of procreation, thus there are strong innate tendencies, typically in the form of feelings, aimed at promoting relevant behavior. These tendencies were designed for a different lifestyle compared to

Bjørn Grinde

bjgr@fhi.no

1 Division of Mental and Physical Health, Norwegian Institute of Public Health, 0213 Oslo, Norway 
what people experience in industrialized societies, which means that sexual behavior may become distorted.

The term 'disease of modernity' implies that a condition is caused by a disparity between the present way of life and the environment of evolutionary adaptation (EEA) (Bennett, 2018; Crawford \& Krebs, 2008; Grinde, 2009a). Diseases of modernity are considered a substantial threat to public health in the developed world (Yach et al. 2006), and the question is whether negative aspects of present sexual behavior ought to be included - if not as a disease, then as a factor reducing quality of life. The EEA presumably reflects as a 'Stone Age,' hunter-gatherer, tribal lifestyle. Features that differ when comparing the EEA with present way of living are referred to as mismatches. As most mismatches are beneficial, it is important to identify the changes that actually cause morbidity or compromise well-being. Mismatches with a negative impact have been referred to as discords (Grinde, 2009a). It can be difficult to distinguish between the two, due to a lack of knowledge and because a mismatch can be beneficial for some people, or some aspects of life, and at the same time have a negative impact on others. Yet, the concept of discords serves as a theoretical foundation for identifying factors that may contribute to various ailments; and, more importantly, suggest preventive measures.

Diseases of modernity are primarily associated with somatic conditions-such as asthma, type 2 diabetes, and nearsightedness - but it seems reasonable to include mental disorders such as depression and anxiety (Grinde, 2009a; Hidaka, 2012; Nesse, 1999). Most ailments presumably occurred in the EEA as well, thus the pertinent question is whether the prevalence is higher today.

The present analysis focuses on whether there are discords affecting sexual behavior; that is, whether features of the present environment are undesirable in terms of their effect on how people relate to sex. The analysis is based on the recent interest in promoting well-being or happiness as a primary aim of society (Helliwell et al. 2020). The term well-being, as used here, covers the mental part of quality of life.

I shall start by discussing the connections between sexual behavior and positive or negative feelings. This effort requires that I first set up a suitable model of the mind and then outline the type of feelings that are likely to be associated with sex. The key topic for the ensuing text is how the present environment, primarily in the form of attitudes and stimuli related to sex and nudity, impact on mood. It seems likely that sex causes more misery, and perhaps less pleasure, today compared to what one might expect in the EEA; thus the text moves on to discuss possible discords. The various aspects of sexual behavior will necessarily be dealt with summarily, as the purpose is to obtain an overview. The analysis takes an evolutionary perspective, but relies heavily on social science research, particularly in regard to sexual behavior and positive psychology.

\section{The Sex Module}

\section{The Concept of Brain Modules}

In order to understand the brain, it is useful to consider it as a collection of modules (Barrett \& Kurzban, 2006). The various modules were shaped by the process of 
evolution as a response to the functions the brain had to perform. Although certain functions rely on certain parts of the brain, most modules require widespread and overlapping nerve circuitry, thus the concept of modules does not imply physical segregation.

Sexual behavior can be considered as depending on one sex module (or one set of modules); the obvious, primary function is to propagate the genes. The concept of a sex module, as used here, includes behavior and feelings leading toward intercourse. If the conditions of life differ from that of the EEA, the sex module can be distorted in the direction of aberrant behavior and altered mental impact.

Catholics traditionally claim that procreation should be the only reason for having sex. At least two mammalian species are not designed to be 'good Catholics' in that their sex modules have a dual function. In the bonobos, sex serves the purpose of group cohesion (Clay \& de Waal, 2015). This may be partly true for humans as well, but here the more obvious purpose is parent bonding (Lovejoy, 1981). Most mammals do not have parental bonding, and even those that do form couples, tend to limit their sexual activity to when the female is in estrus.

A key point is that sexual behavior is largely driven by feelings. I use the term feelings to include sensations (pleasant or unpleasant experiences due to signals from external or internal sensory organs) and emotions (Grinde, 2012). The latter encompasses all other forms of feelings, but typically involves interpersonal relations. Feelings are either positive or negative; that is, they involve rewards or punishment delivered by the brain in the form of respectively pleasure or pain.

The conscious experience of a feeling is based on input from two different sets of modules. The positive or negative aspect is due to the contribution of the mood modules. They were presumably introduced at the amniotic stage of vertebrate evolution as a strategy to optimize behavior (Cabanac, 1999; Grinde, 2018). The evolutionary function of pleasure and pain is to help an individual evaluate behavioral options. Positive feelings lead us toward what is good for the genes, such as nutrients and sexual partners; while negative feelings direct us away from anything that can be harmful, such as injury and predators.

Based on neurological research, the mammalian brain has three distinct mood modules (Berridge \& Kringelbach, 2015; Leknes \& Tracey, 2008). Negative feelings are based on a single pain module, which is why all sorts of negative feelings, whether in the form of jealousy or physical pain, can be labelled as 'pain.' The nerve circuits responsible are, at least to a large extent, shared. The reward system is divided into two modules. The seeking module (also referred to as wanting or motivating) stimulate the individual to seek opportunities and motivate for relevant action; the liking module (also referred to as consuming) makes sure the opportunities are exploited. The effect of the seeking and liking modules can be exemplified by a person who first follows the smell of a bakery and then eat a cake. The classification of the two reward modules is based on their neurobiology, but also makes sense in evolutionary terms (Grinde, 2012). That is, in order to obtain what is good for the genes, it is necessary to first motivate the individual for action and then ensure that the opportunity ends with actual consummation. A single pain module suffices for whatever the individual should avoid. Thus, the three modules reflect an economic way of taking care of the relevant needs. Various studies support 
the notion that the same neurological circuits create the positive or negative aspect regardless of the type of situation or stimuli (Blood \& Zatorre, 2001; Leknes \& Tracey, 2008; Lieberman \& Eisenberger, 2009).

As pointed out above, the actual experience is based on input from a second set of modules. I shall refer to this set as type modules. They add the specific quality to the experience; that is, they explain why, for example, being rejected feels so different from hurting ones knee; or eating a cake is different from an orgasm.

In this model of the mind, the type modules activate the mood modules. The latter solely adds the positive or negative component of the experience. It is relevant to note that a particular type module can activate either pleasure or pain. Fear is a characteristic example, normally it activates the pain module, but a fearful situation can also offer pleasure, as in the case of the adrenalin kick of a climber. Which mood module that is active can shift rapidly; if the climber slips, the experience changes to panic. The main 'switches' for turning the mood modules on or off belong to the unconscious part of the brain, for the obvious reason that they are meant to control you rather than you controlling them.

Well-being, or happiness, can be construed as the net activity of the mood modules; that is, the pleasures minus the pain (Grinde, 2012). There are some caveats to this definition. For one, the reward modules are also activated in situations that are not associated with typical hedonic pleasures; for example, in connection with friendship or having a meaningful life. Thus, the definition includes what is typically considered eudemonic forms of satisfaction. Two, the mammalian brain is presumably designed with a positive feeling as the default. As long as the pain module is not activated, the reward modules dominate, implying that people tend to be content. The problem is that too many people suffer from excessive negative feelings, such as those associated with anxiety and depression (Grinde, 2015). Avoiding unwarranted activity of the pain module is arguably more important than seeking short-term delights. This contention seems reasonable in the case of sex. The sensual pleasures associated with sex tend to be limited to a minor fraction of the day; while a negative emotional impact, for example due to guilt or jealousy, can permeate the day.

It seems likely that humans engage in sex primarily because of the substantial dose of rewards offered by the brain. This interpretation suggests that behavior, such as masturbation, does not need to reflect any biological advantage. In the EEA, excessive time spent on unproductive sex would be taken as an example of evolution not designing optimal organisms; in the present setting, there is the additional factor that behavior may be skewed when the environment differs from that of the EEA. As the present analysis focuses on well-being, skewed behavior is only a problem if it has a negative effect on mood.

\section{How Sex Activates the Mood Modules}

As sex is in the interest of the genes, the sex module primarily activates the reward modules; that is, both the sensations and the core emotions (such as love and desire) are positive. However, sex can indirectly activate negative feelings in various ways. Whether a particular situation is conceived as positive or negative depends on a 
range of factors, including personal evaluation. As in the case of the climber, which mood module that is active can shift on short notice; guilt can, for example, turn the gratification of an intercourse into a disagreeable experience.

Humans have evolved a unique combination of forming couples while being highly social (Fowers, 2015). Evolution introduced a range of emotional modules designed to enhance both types of interactions. Arguably, both the most important pleasures and the most important pains are associated with interpersonal relations (Grinde, 2009b). The conjecture may explain why social factors offer the best correlates to scores on subjective well-being or life satisfaction (Gallagher \& VellaBrodrick, 2008; Layard, 2005). In the above section, I suggested that the default state of the human mind is one of contentment. If so, a rational approach to the pursuit of happiness is to avoid negative emotions elicited by social interactions. In short, one should aim to have positive relations with both family, friends, and those one have intimate contact with.

I shall briefly describe how sexual behavior can activate the pain module. The positive feelings and emotions associated with sex are reasonably obvious.

Most communities have rules regarding sexual behavior. We are designed to follow moral guidelines and are equipped with a set of modules-including conscience, guilt, and shame - to ensure we comply. That is, the moral rules easily induce negative emotions when violated. Doing something regarded as wrong by peers typically implies a considerable emotional burden. For example, having sex with other individuals than the main partner can cause jealousy. Another issue is that of regret, or feeling misused, after being involved in sexual activity. It is also relevant to mention indignation, resentment, and disgust. These sentiments are typically caused by acts performed by others, but can also be elicited by personal actions or thoughts. Envy and spite constitute a somewhat different set of relevant emotions.

Some people develop a sense of inadequacy, or feel insecure, due to either bodily appearance or sexual performance. It is typically a question of having an inferiority complex-induced by a notion that others are prettier, sexier, more virile, or simply more popular.

The punishing feelings mentioned above reflect brain functions installed by evolution, which means they must have been engaged in the EEA as well. The question is whether the frequency of activation, or average impact on the mind, is more pronounced today. One problem when trying to answer this question is that the same emotions are also engaged in other situations; thus it is difficult to discern the specific role of sex. For example, sexual desires can cause shame, but so can a range of other factors; and jealousy can be due to the partner having sex with someone else or that the partner spends too much time with friends.

In addition to the above list of negative emotions, there are sensory, or physical, nuisances associated with sex, such as genital pain. These are relevant in that they are likely to affect well-being; but, arguably, the more pertinent aspect of sex is the emotional impact. The emotional pleasures and pains are not necessarily more intense than those classified as sensory or physical, but over a lifetime, they seem likely to have a larger impact on well-being.

The sex module is not the same in males and females. In biology, one way of defining female is as the gender (here used in the sense biological sex) investing 
more in the offspring. The difference in investment corresponds with a key difference in mating strategy. Females tend to be more fastidious and selective as to whom they mate with; while males are more promiscuous, they desire more partners and have a lower threshold for engaging in sex (Ford \& Beach, 1951; Kruglanski \& Stroebe, 2012).

The question for the present discussion is how to ensure that the sex module activates the reward modules rather than the pain module-regardless of gender. The relevant rewards are not necessarily that different; both genders take pleasure in the sexual act, and both can appreciate the intimacy, the skin contact, and the bonding. The differences appear to be more distinct in the case of negative emotions, brought on by the contrasting mating strategies. For example, women are more prone to feel abused, or ending up with regret, after engaging in sex (Galperin et al., 2013). Men, on the other hand, seem more likely to experience frustration due to situations where they feel enticed to anticipate sex. Another likely difference is that the male brain is designed to become jealous over physical infidelity, while the female brain is more inclined to react to emotional infidelity (Ogas \& Gaddam, 2011).

\section{A Disease of Modernity?}

\section{Sexual Behavior Then and Now}

It is challenging to assess the emotional burden of sex in present society, and even more challenging to suggest how sexual behavior functioned in the EEA. Yet, there are data allowing for an educated opinion. The issue will initially be probed in two ways: One, are there changes in sexual preferences and desires; and two, is there an increase in sexual dysfunctions. Besides research in sexology, cross-cultural comparison of traditional societies and observations of animal behavior offer relevant information. The subsequent discussion on possible contributing discords (negative mismatches) adds pertinent background. Admittedly, this is a somewhat indirect way of answering the key question; that is, whether sexuality today has a less positive effect on well-being.

The primary function of sex is propagation, thus one expects that sexual desires are directed at coitus. According to anthropological literature (Ford \& Beach, 1951), coitus is by far the most common practice; yet, in most cultures there appear to be a reasonable amount of sexual activity that is not aimed at fertilization. The observation makes sense in that humans use sex to enhance bonding. Sex without pregnancies thus serves a genetic purpose; consequently, the use of contraceptives, or interrupted ejaculation, can be considered normal. Furthermore, as sex is strongly reward-driven, one should expect self-stimulation. This is indeed the case, based on the anthropological descriptions of tribal people as well as observations of other species of mammals (Ford \& Beach, 1951). Traditional cultures are aware of the possibility for self-stimulation; the practice is typically not banned, but discouraged as being less desirable.

In the following analysis, it is important to keep in mind what sort of behavior that is adverse. Sexual activities are not necessarily harmful just because they are 
odd (in a statistical sense) or off (in the sense of not contributing to procreation). The question is whether the activity is suboptimal when assessed in terms of its impact on well-being. Moreover, a negative impact can be due to a particular cultural setting. Any behavior labelled as undesirable by peers is likely to have a negative impact due to the modules associated with conscience. When a person transgresses what is considered proper sexual conduct, he or she tends to be antagonized; and this situation typically implies negative emotions. In short, 'abnormal' sex easily has a negative impact, but the situation can be ameliorated by changing the moral attitudes.

\section{Sexual Preferences}

Probing sexual preferences is one way of illuminating the question of whether the sex module is distorted in present society. Although variations in sexual desires and behavior can be enriching, they may also have a negative impact on well-being.

Sexual preferences can be examined by investigating what sort of stimuli that trigger sexual arousal. There is a wide range of interests, most, if not all, are catered to by the Internet. Research into the use of search terms thus offers relevant information. Men are by far the larger consumer of porn sites with explicit sex or nudity, while women take more interest in sites offering stories that cater to the their ideals as to partner choice (Carvalho et al., 2013; Hald, 2006; Salmon \& Fisher, 2018; Tyson et al., 2015).

The most common search words point to what may be considered normal sexual interests (Ogas \& Gaddam, 2011; Salmon \& Fisher, 2018; Tyson et al., 2015). Men search for young and willing females with sexual appeal. A virgin look is preferred, as may be expected as a virgin is not already pregnant with someone else, and thus offers a better chance of procreation. However, there is also a distinct desire for older women, typically aimed at those already with a partner, reflected in search words such as MILF (Mothers I'd Like to Fuck), cheating wife, and granny. Older and married females make sense as a male strategy; if the woman gets pregnant, his genes will be passed on with a minimum of personal effort.

Although most of the interest in pornography appears to be in line with what one would expect reflects innate tendencies, there is also considerable interest in porn (and real-life experience) for content that is less likely to reflect the 'whispering' of the genes. Examples include fetishes for dead bodies, feet, animals, or female clothing items. Obscure preferences are generally referred to as paraphilia. Although odd sexual behavior is observed in animals as well, including attempts to have sex with dead bodies, they seems to be rare at least for animals living in the wild (Ford \& Beach, 1951). The rare examples may reflect an 'overflow' of sexual desires in situations where normal sex is not available. This seems to contrast the situation in humans where paraphilic urges can become the main focus of sexual interest. Paraphilias also seem to be rare in the anthropological literature on tribal societies, thus the present prevalence is likely a consequence of the modern environment. The question of skewed desires probably concerns men more than women. 
Although most sexual desires are reflected in porn on Internet, some are less easily available due to legal issues. This is certainly the case with pedophilia. It seems biologically normal to be sexually interested in adolescent females as long as they have anatomical features suggestive of maturation; an interest in infants is less obvious, but well known for both heterosexual and gay human males. With the exception of bonobos (de Waal \& Lanting, 1997), sex with juveniles is rare in animals. In an Internet-based, anonymous questionnaire, $4.1 \%$ responded that they had sexual fantasies about children, and 3.2\% admitted to having abused infants (Dombert et al. 2016). Based on the interest in search words such as Lolita and preteen, this may be an underestimate of the actual desire for having sex with juveniles (Hald \& S Stulhofer, 2016). In several tribal societies, it is common for parents to fondle the genitals of their infants (Ford \& Beach, 1951). This practice, however, is not necessarily pedophilic, as it does not require sexual arousal for the adult. In some traditional cultures, true sex between children and adults is not only allowed, but encouraged (Ford \& Beach, 1951; Kelly \& Lusk, 2013).

The perpetuation of pedophilia in modern societies, in spite of the ostracism, may reflect a resonance with innate urges in this direction. One possible explanation is that the trait is shared with the bonobos. If so, pedophilia should be only a minor diversion; not, as appears to be the case today, the main driving force of sexual behavior in a reasonable number of individuals. The latter observation suggests that the preference reflects a distorted sex module. The practice is unlikely to gain acceptance in society, thus pedophilic desires are expected to have a negative impact on well-being.

Rape-like behavior is well known in animals (Smuts \& Smuts, 1993). Whether the species form bonds between parents or not, it makes evolutionary sense for the male to have forced sex with a female. Humans have certain advantages when it comes to rape in that we have hands to hold the victim down and language to form threats. As might be expected, rape occurs in both the tribal setting and in modern societies (Ford \& Beach, 1951). Although a desire for the use of force can be construed as normal in males, it constitutes a minor part of all sexual encounters. The use of force is likely to entail a heavy load of negative feelings for the victim, and should therefore be discouraged.

Interestingly, both genders willingly participate in activities that involve violence or coercion. The point is reflected in the use of search terms such as BDSM, bondage, dominance, spanking, slave, sadism, and masochism (Ogas \& Gaddam, 2011)-here collectively referred to as rough sex. There is limited evidence for a related interest in tribal societies, with one exception. It is reasonably common to inflict pain on the partner during intercourse, typically in the form of scratching and biting, as this is considered to enhance sexual pleasure (Ford \& Beach, 1951). Yet, the forms of behavior reflected by the search terms listed above seem to be novel, which suggests that the practice, or at least the prevalence and degree of devotedness, is a consequence of the modern environment.

Apparently, participants obtain pleasure from rough sex that goes beyond what they would get from normal sex. As pointed out when explaining the concept of mood modules, situations that typically elicit pain can be converted to yield pleasure. Even signals stemming from pain receptors can have a positive connotation, as 
observed in the case of people who take delight in self-harming (Edmondson et al., 2016). In other words, physical pain may actually enhance the enjoyment of sex. A similar argument can be made in the case of submission and bondage. In fact, bondage forms of sex may be as satisfying as a more regular practice (Pascoal et al., 2015). Another point is that women may appreciate (mock) rape because it offers an experience of being considered particularly attractive (Hazen, 1983). Yet, the stigmatization of rough sex can result in a negative impact on well-being.

Self-stimulation is presumably common everywhere, but in modern societies it probably stands for a larger proportion of sexual activity compared to tribal cultures (Prause, 2019; Regnerus et al., 2017). It seems likely that the increase is at least partly due to the opportunities offered by pornography. Stone Agers would probably have taken an interest in porn if it had been available; as even male macaques willingly 'pay' (by trading fruit) for the opportunity to view pictures of female macaques in heat (Deaner et al., 2005). The pertinent question is whether the use of pornography, and the concomitant high prevalence of self-stimulation, affects the functioning of the sex module in an undesirable way. Masturbation does offer sexual pleasures, and consequently contributes to well-being, but the practice may also have less desirable effects. The focus on self-stimulation may imply less focus on sex with a partner, which could reduce the strength of a relationship. Moreover, depending on the kind of stimuli sought, it might have an undesirable effect in that masturbatory fantasies can reinforce and broaden a particular form of arousal (Nolen-Hoeksema, 2013). That is, if the focus is on violence, or on sex with juveniles, these desires may be strengthened.

Homosexual activity is common in mammals, and particularly so in species lacking the pheromone-associated TRPC2 gene; that is, in Old World monkeys, apes and man (Pfau et al., 2019). In addition to sexually motivated behavior, many species use mock mounting of another individual, typically of the same gender, to confirm social rank. Obviously, heterosexual behavior is even more common, again with the possible exception of bonobos (de Waal, 2007). Exclusively homosexual individuals seem to be extremely rare, at least in the wild, thus the observed homosexual behavior is typically a question of bisexuality. As to humans, it seems relatively common for males to take a sexual interest in other males, as indicated by the popularity of search words such as big cock (Salmon \& Fisher, 2018), and by the employment of services from shemales. A reasonable proportion of modern humans declare that they have a bisexuals disposition, typically estimated to be $5-20 \%$ depending on the population and type of data; while approximately $1 \%$ claims to be solely interested in one's own gender (Savin-Williams et al., 2012; Tyson et al., 2015). As in the case of other, genetically unproductive, forms of sex; one would expect same gender sex to be a diversion rather than the main focus.

Several factors may explain why homosexual activity is common in our species. We have a strong sex drive, and a strong drive seems more likely to dispose for diverse behavior. Sex has the additional purpose of bonding; and, as in the case of bonobos, we collaborate with individuals of the same gender. That is, one would expect homosexuality to promote cooperation; a phenomenon that apparently is relevant in several species of mammals (Douglas, 2009; Packer \& Pusey, 1987). Yet, the relatively high prevalence of exclusive homosexuals may also reflect certain features 
of modern societies; for example, condemning the behavior may create a need to choose side. If so, it is a case of a distorted sex module.

Bisexuality seems to be a normal feature of the human sex module, the suppression in modern societies is a likely discord. If so, the present problem is a suboptimal use of same gender sexual enjoyment, as well as the negative emotions caused by the attempt to suppress such activity.

\section{Sexual Disorders}

The diagnostic manuals used in connection with mental health, such as Diagnostic and Statistical Manual of Mental Disorders (DSM-5) published by APA (American Psychiatric Association), focus on two types of disorders related to sexual behavior: paraphilia and sexual dysfunctions. A paraphilia implies a sexual preference that deviates from the norm, but morbid paraphilia is typically narrowed down to behavior that causes suffering or humiliation of oneself or non-consenting others (Joyal, 2014). The restricted use of the term is in line with the stance of the present analysis, in that the issue is not whether a preference may classify as abnormal, but whether it reduces the quality of life.

The more common forms of sexual dysfunctions concern problems like premature ejaculation, lack of erection, and lack of libido. In Western countries, these conditions affect some $30 \%$ of adult men and $40 \%$ of adult women (Laumann et al., 1999; Lewis et al., 2004; Shifren et al., 2008). The higher prevalence among women does not necessarily reflect less sexual satisfaction, as women on average seem to be more satisfied with their sex life than men (Tyson et al., 2015). Perhaps women are more likely to accept a situation as being problematic and respond accordingly. There is not much in terms of comparable anthropological data, but the numbers suggest that the present environment is responsible for an increase. It seems unlikely that evolution would design a sex module that malfunctions in such a large proportion of the population. It should be mentioned that the above prevalence include individuals where the primary problem is physical rather than mental.

Based on the discussion so far, I infer that the sex module is distorted in a way that is likely to reduce quality of life. The well-being of the population should improve if we can identify, and restore, relevant discords. The question is: What sort of discord are likely to be responsible for the present burden? Examining possible discords adds evidence to the above inference, by offering an explanation, and it points in the direction of possible preventive measures.

\section{Relevant Discords}

\section{Formative Years}

When looking for discords that may have a negative effect on the mind, it makes sense to focus on the first years of life as the brain develops proportionally more in this period. Both mental and bodily functions need to mature, and do so in 
interactions with the environment, but the mental functions are perhaps more vulnerable to altered conditions. The question is whether there are features of the early life situation that have an undesirable effect on the maturation of the sex module.

In mammals such as goats and sheep, sexual interests are imprinted in males during adolescence (Ogas \& Gaddam, 2011). In fact, there appear to be a critical period for males to develop sexual desires in several species (Ford \& Beach, 1951); for example, chimpanzees that are refused sexual play during infancy, later struggle to perform sexually (Yerkes \& Elder, 1936).

In the case of humans, the restrictions we place on the child's experience with nudity and sex is a possible discord. In most modern societies, people tend to hide their sexual activity, and their nude bodies, not just for other adults, but also for their infants. In other primates, sex is generally not concealed, and the anthropological literature suggests that the same was the case in the EEA (Ford \& Beach, 1951; Frayser, 2003; Josephs, 2015). That is, sex in primates, and presumably in Stone Age humans, is concealed in one particular context: when having sex with an illegitimate partner. In humans that typically implies a partner engaged with someone else, in other species the female may 'belong to' a higher-ranking male.

Infants enact sex play with peers from as early as 3-4 years of age, and boys of this age may experience a sort of 'orgasm' (Kinsey et al., 1998; Martinson, 1976). The Human Relations Area Files include several cultures where children are allowed to learn sex through observations and play (Ember \& Fischer, 2017); much as they learn about other aspects of adult behavior. It seems reasonably common that children explore the genitals of their parents; and mothers stimulate the genitals of their children, either in order to sooth and comfort them or simply to offer them pleasure. Juvenile sexuality appears to be common in other primates as well, particularly in the case of males (Dixson, 2012). Young, male chimpanzees mock mate with any female that allows them, including their own mothers (de Waal, 2007). It is common for infants to take an interest in their genitals, as well as those of others, and they obtain pleasure from genital stimulation from an early age (Josephs, 2015). Those with frequent exposure of this sort, tend to be more sexually active later in life; perhaps surprisingly, this seems to be the case even if the exposure is in the form of abuse (Browning \& Laumann, 1997).

The lack of sexually related input, including both visual and direct genital stimulation, may restrict or distort the development of the sex module, and thus contribute to a situation where sex does not fulfil its potential for enhancing well-being. The situation is not improved by the tendency to offer negative feedback on any interest in sexual organs. Children learn that nudity and sex is taboo. They are likely to be reprimanded whether they touch their own genitals or those of parents or peers. An increase in the level of negative emotions such as guilt, shame, and regret is a likely consequence. The experience of infants may also contribute to the formation of aberrant desires.

It is not obvious that the capacity to derive pleasure from genital stimulation should be present in infants; female nipples do not seem to become particularly erogenous until the development of breasts (Robinson \& Short, 1977). The early genital sensitivity suggests that infants are meant to engage in sexual play. There is 
no danger of inbreeding in the case of prepubertal youngsters, thus activity involving parents or sibling does not pose any genetic problem.

Although the brain expand the most in the early years of life, in the case of the sex module, there is a second boost of development during puberty. The points made as to infant environment are to some extent relevant for this period of life as well.

\section{Ethical Rules}

The human population has seen an enormous expansion since the Stone Age; we have moved from a tribal setting to that of giant cities. The situation is likely to include discords and concomitant stress (Grinde, 2009b). We regularly interact with a considerable number of strangers, and many people lack anything resembling the close-knit network of a tribe. One consequence is particularly pertinent regarding the present analysis. The loss of a social organization based on tribal units, where people would tend to care for fellow members due to their long-term relations and interdependence, gave rise to changes in ethical rules. In order to restrain negative outcomes of encounters with strangers, we evolved advanced religions with moralizing gods (Whitehouse et al., 2019).

These religions, including Christianity and Islam, tend to condemn sex that is not concealed, involves unmarried individuals, and is not aimed at procreation. The presumed rational behind the rules was to prevent unwarranted consequences of our strong sexual drive; including undesired pregnancies, the spread of infectious diseases, the dissolution of marriage, as well as rape and sexual assault. Today these problems can be dealt with by other means; we have contraceptives, treatment for infections, childcare depends less on having two parents, and presumably a more efficient law enforcement. Yet, the religious rules tend to persist; exemplified by the restriction on nudity and sex in films as opposed to the relative lenience on violence.

Although rules related to sexual behavior and dress codes are present in typical tribal societies, they tend to be more relaxed compared to industrialized nations (Ford \& Beach, 1951). It seems likely that the default setting for humans is a more open and permissive attitude to nudity and sex.

Evolution installed strong emotions meant to secure conformity to group regulations. In the EEA, being ostracized or expelled from the group could have dire consequences; the rational for feelings such as conscience, shame, and guilt, is to avoid that to happen. Social relations are less important for the genes today, but the genes have not adapted to a situation where life can easily be lived in solitude. Thus, the relevant emotions are as important for well-being now as in the Stone Age. The present setting, with stricter moral rules, presumably cause these negative emotions to have a greater impact on the mind.

In short, the present attempt to regulate sexuality is likely to reduce quality of life. Moreover, the emotional burden of sensing that even normal desires are considered amoral, may actually promote sexual abuse. The point is substantiated by the observation that a leniency to porn correlates with lower levels of violence toward women (Diamond, 2010). 


\section{Availability of Stimuli}

Up until some 50-100 thousand years ago, people were presumably mostly naked (Kittler et al., 2003). The dating is based on the evolutionary split between head lice and body lice; the latter depends on the use of clothing in order to spread between individuals and is therefore expected to have evolved after that practice became reasonably common.

The strict dress codes that permeate modern societies are probably a consequence of population density. The rational is the same as for the ethical rules discussed above: By covering sexually relevant anatomical features there will be less unwarranted sexual desire. The lack of a normal exposure to these features is certainly a mismatch and perhaps a discord. The present situation, where these stimuli are available in particular settings, such as pornographic sites on Internet, may aggravate the situation. Rather than seeing the full range of bodily types, we are exposed to select models. The high standard of these models, whether catering to males or females, make it more difficult to enjoy normal sexual stimuli-that is, less perfect bodies and less ideal male characters. The consequences may include unwarranted negative feelings when people assess themselves, and lack of sexual fulfilment if a person does not find the spouse sufficiently desirable.

It seems likely that the use of Internet porn can contribute to sexual problems (Park et al., 2016). The user typically masturbates to porn that; for one, offers unlimited access to novel and ideal sex objects; and two, caters to peculiar preferences. The combination is a form of superstimuli that is not available in real life; the person may experience erectile dysfunction, lack of libido, or low sexual satisfaction when with a partner. One may argue that the potential for sexual pleasures is catered for by the masturbation, but the bonding part and the skin-to-skin contact is missing.

Any stimuli that engage the reward modules of the brain can cause addictive behavior. Not surprisingly, sexual stimuli on the Internet is known to cause sexual addiction, also referred to as hypersexuality (Griffiths, 2012). The condition has a negative impact on well-being when the behavior is excessive in a way that is unfavorable for other aspects of life, such as career or personal relations.

Internet-based stimuli may trigger undesirable sexual behavior (Fortin et al., 2018; Nolen-Hoeksema, 2013), but they also offer a chance to relieve sexual cravings in a safe way. We lack sufficient data to determine how these pros and cons balance. Although it may be preferable to direct sex toward real life partners, Internet does offer a substitute with a potential for enhancing well-being. Moreover, an attempt to abolish porn seems like a dubious strategy.

\section{Conclusion}

The above discussion presents indirect evidence for the idea that modern societies offer a suboptimal environment in terms of how sex effects quality of life. The more troublesome aspects are perhaps: One, a distorted sex module due to the way we deal with infants; two, an elevated level of negative emotions such as guilt and shame due to strict ethical rules; and three, a reduced harvest of positive feelings due to a reduction 
in shared sexual activity. The third point may derive from the first two; people who associate sex with negative emotions have reduced sexual desire (Woo et al., 2011). Whether or not the situation qualifies as a disease of modernity, there seems to be room for improvements.

As pointed out above, the key issue is not whether a behavior is aberrant, but how it serves people. Any form of sex has the potential to enhance happiness of consenting participants; and in an over-populated world, a focus on unproductive sex has obvious advantages. Yet, sex that does not conform to cultural norms tends to have negative aspects; and a culture without any stigma on behavior seems unlikely_and, arguably, not desirable. Furthermore, it may be easier to find sexual partners, and concomitant satisfaction, if desires are in line with the majority of the population. On the other hand, it is difficult to change adult sexual inclinations; thus the obvious option in order to improve well-being is to work toward a more accepting culture-at least regarding behavior without any negative impact beyond being stigmatized. In the long run, dealing with the proposed discords of industrialized societies may normalize desires.

It has been shown that the level of sexual activity correlates with well-being (Blanchflower \& Oswald, 2004; Cheng \& Smyth, 2015), but so does the quality of our social network (Gallagher \& Vella-Brodrick, 2008). It is not obvious whether better relations imply more sex, or more sex help build better relations. In any case, a positive and accepting attitude to sex is likely to improve both intimate relations and the amount of pleasure obtained from sex.

Modern societies have many advantages compared to the EEA-based life, but also detrimental aspects. While it is difficult to impact on biological evolution, we do have the means to influence cultural evolution. That is, we should aim to create an environment that offers an average quality of life surpassing any previous or present human society. Making the most of our sex module is an important element in this endeavor.

Funding Open access funding provided by Norwegian Institute of Public Health (FHI). No particular funding.

Data availability Not applicable.

Code availability Not applicable.

\section{Declarations}

Conflict of interest The author declare that he/she has no conflict of interest.

Ethical approval This article does not contain any studies with human participants performed by the author.

Open Access This article is licensed under a Creative Commons Attribution 4.0 International License, which permits use, sharing, adaptation, distribution and reproduction in any medium or format, as long as you give appropriate credit to the original author(s) and the source, provide a link to the Creative Commons licence, and indicate if changes were made. The images or other third party material in this article are included in the article's Creative Commons licence, unless indicated otherwise in a credit line to the material. If material is not included in the article's Creative Commons licence and your intended use is not permitted by statutory regulation or exceeds the permitted use, you will need to obtain permission 
directly from the copyright holder. To view a copy of this licence, visit http://creativecommons.org/licen ses/by/4.0/.

\section{References}

Barrett, H. C., \& Kurzban, R. (2006). Modularity in cognition: Framing the debate. Psychological Review, 113(3), 628-647. https://doi.org/10.1037/0033-295X.113.3.628

Bennett, K. (2018). Environment of evolutionary adaptedness (EEA). Encyclopedia of Personality and Individual Differences, 1-3.

Berridge, K. C., \& Kringelbach, M. L. (2015). Pleasure systems in the brain. Neuron, 86(3), 646-664

Blanchflower, D. G., \& Oswald, A. J. (2004). Money, sex and happiness: An empirical study. Scandinavian Journal of Economics, 106(3), 393-415

Blood, A. J., \& Zatorre, R. J. (2001). Intensely pleasurable responses to music correlate with activity in brain regions implicated in reward and emotion. Proceedings of National Academy of Science USA, 98(20), 11818-11823. https://doi.org/10.1073/pnas.191355898

Browning, C. R., \& Laumann, E. O. (1997). Sexual contact between children and adults: A life course perspective. American Sociological Review, 540-560.

Cabanac, M. (1999). Emotion and phylogeny. Japanese Journal of Physiology, 49(1), 1-10

Carvalho, J., Gomes, A. Q., Laja, P., Oliveira, C., Vilarinho, S., Janssen, E., et al. (2013). Gender differences in sexual arousal and affective responses to erotica: The effects of type of film and fantasy instructions. Archives of sexual behavior, 42(6), 1011-1019

Cheng, Z., \& Smyth, R. (2015). Sex and happiness. Journal of Economic Behavior Organization \& Environment, 112, 26-32

Clay, Z., \& de Waal, F. B. (2015). Sex and strife: Post-conflict sexual contacts in bonobos. Behaviour, $152(3-4), 313-334$

Crawford, C., \& Krebs, D. (2008). Foundations of evolutionary psychology. Psychology Press.

de Waal, F. (2007). Chimpanzee politics: Power and sex among apes. JHU Press.

de Waal, F., \& Lanting, F. (1997). Bonobo: The forgotten ape. University of California Press.

Deaner, R. O., Khera, A. V., \& Platt, M. L. (2005). Monkeys pay per view: Adaptive valuation of social images by rhesus macaques. Current Biology, 15(6), 543-548

Diamond, M. (2010). Porn: Good for us? Scientific examination of the subject has found that as the use of porn increases, the rate of sex crimes goes down. The Scientist, 24(3), 29-30

Dixson, A. (2012). Primate sexuality: Comparative studies of the prosimians, monkeys, apes, and humans. (2nd ed.). Oxford University Press.

Dombert, B., Schmidt, A. F., Banse, R., Briken, P., Hoyer, J., Neutze, J., et al. (2016). How common is men's self-reported sexual interest in prepubescent children? The Journal of Sex Research, 53(2), 214-223

Douglas, K. (2009). Homosexual selection. New Scientist, 204(2737), 48-51

Edmondson, A. J., Brennan, C. A., \& House, A. O. (2016). Non-suicidal reasons for self-harm: A systematic review of self-reported accounts. Journal of Affective Disorders, 191, 109-117

Ember, C., \& Fischer, M. D. (2017). Using eHRAF world cultures with other cross-cultural samples.

Ford, C. S., \& Beach, F. A. (1951). Patterns of sexual behavior. Harper.

Fortin, F., Paquette, S., \& Dupont, B. (2018). From online to offline sexual offending: Episodes and obstacles. Aggression and violent behavior, 39, 33-41

Fowers, B. (2015). The evolution of ethics: Human sociality and the emergence of ethical mindedness. Springer.

Frayser, S. (2003). Cultural dimensions of childhood sexuality in the United States. In Sexual development in childhood (Vol. 7, pp. 255-273). Indiana University Press.

Gallagher, E. N., \& Vella-Brodrick, D. A. (2008). Social support and emotional intelligence as predictors of subjective well-being. Personality and Individual Differences, 44(7), 1551-1561. https://doi.org/ 10.1016/j.paid.2008.01.011

Galperin, A., Haselton, M. G., Frederick, D. A., Poore, J., Von Hippel, W., Buss, D. M., et al. (2013). Sexual regret: Evidence for evolved sex differences. Archives of Sexual Behavior, 42(7), 1145-1161

Griffiths, M. D. (2012). Internet sex addiction: A review of empirical research. Addiction Research \& Theory, 20(2), 111-124 
Grinde, B. (2009a). Can the concept of discords help us find the causes of mental diseases? Medical Hypotheses, 73(1), 106-109. https://doi.org/10.1016/j.mehy.2009.01.030

Grinde, B. (2009b). An evolutionary perspective on the importance of community relations for quality of life. ScientificWorldJournal, 9, 588-605. https://doi.org/10.1100/tsw.2009.73

Grinde, B. (2012). The biology of happiness. Springer.

Grinde, B. (2015). Why negative feelings are important when assessing well-being. Journal of Happiness Studies. https://doi.org/10.1007/s10902-015-9667-z

Grinde, B. (2018). Did consciousness first evolve in the amniotes? Psychology of Consciousness: Theory, Research, and Practice, 5, 239-257. https://doi.org/10.1037/cns0000146

Hald, G. M. (2006). Gender differences in pornography consumption among young heterosexual Danish adults. Archives of sexual behavior, 35(5), 577-585

Hald, G. M., \& Štulhofer, A. (2016). What types of pornography do people use and do they cluster? Assessing types and categories of pornography consumption in a large-scale online sample. The Journal of Sex Research, 53(7), 849-859

Hazen, H. (1983). Endless rapture rape, romance, and the female imagination. Scriber.

Helliwell, J. F., Layard, R., Sachs, J., \& Neve, J. E. D. (2020). World Happiness Report 2020. Sustainable Development Solutions Network.

Hidaka, B. H. (2012). Depression as a disease of modernity: explanations for increasing prevalence. Journal of affective disorders, 140(3), 205-214

Josephs, L. (2015). How children learn about sex: A cross-species and cross-cultural analysis. Archives of Sexual Behavior, 44(4), 1059-1069

Joyal, C. C. (2014). How anomalous are paraphilic interests? Archives of sexual behavior, 43(7), $1241-1243$

Kelly, R., \& Lusk, R. (2013). Theories of pedophilia. The Sexual Abuse of Children, 1, 168-203

Kinsey, A. C., Pomeroy, W. B., Martin, C. E., \& Gebhard, P. H. (1998). Sexual behavior in the human female. Indiana University Press.

Kittler, R., Kayser, M., \& Stoneking, M. (2003). Molecular evolution of Pediculus humanus and the origin of clothing. Current Biology, 13(16), 1414-1417

Kruglanski, A. W., \& Stroebe, W. (2012). Handbook of the history of social psychology: Psychology Press.

Laumann, E. O., Paik, A., \& Rosen, R. C. (1999). Sexual dysfunction in the United States: prevalence and predictors. JAMA, 281(6), 537-544

Layard, R. (2005). Happiness-Lessons from a new science. Penguin.

Leknes, S., \& Tracey, I. (2008). A common neurobiology for pain and pleasure. Nature Reviews Neuroscience, 9(4), 314-320. https://doi.org/10.1038/nrn2333

Lewis, R. W., Fugl-Meyer, K. S., Bosch, R., Fugl-Meyer, A. R., Laumann, E. O., Lizza, E., et al. (2004). Epidemiology/risk factors of sexual dysfunction. The Journal of Sexual Medicine, 1(1), 35-39

Lieberman, M. D., \& Eisenberger, N. I. (2009). Neuroscience pains and pleasures of social life. Science, 323(5916), 890-891

Lovejoy, C. O. (1981). The origin of man. Science, 211(4480), 341-350

Martinson, F. M. (1976). Eroticism in infancy and childhood. Journal of Sex Research, 12(4), 251-262

Nesse, R. (1999). Proximate and evolutionary studies of anxiety, stress and depression: Synergy at the interface. Neuroscience \& Biobehavioral Reviews, 23(7), 895-903

Nolen-Hoeksema, S. (2013). Abnormal psychology. (6th ed.). McGraw-Hill.

Ogas, O., \& Gaddam, S. (2011). A billion wicked thoughts: What the Internet tells us about sexual relationships. Penguin.

Packer, C., \& Pusey, A. E. (1987). The evolution of sex-biased dispersal in lions. Behaviour, 101(4), 275-310

Park, B., Wilson, G., Berger, J., Christman, M., Reina, B., Bishop, F., et al. (2016). Is Internet pornography causing sexual dysfunctions? A review with clinical reports. Behavioral Sciences, 6(3), 17

Pascoal, P. M., Cardoso, D., \& Henriques, R. (2015). Sexual satisfaction and distress in sexual functioning in a sample of the BDSM community: A comparison study between BDSM and non-BDSM contexts. The Journal of Sexual Medicine, 12(4), 1052-1061. https://doi.org/10.1111/jsm.12835

Pfau, D., Jordan, C. L., \& Breedlove, S. M. (2019). The de-scent of sexuality: Did loss of a pheromone signaling protein permit the evolution of same-sex sexual behavior in primates? Archives of Sexual Behavior, 8, 639-649

Prause, N. (2019). Porn is for masturbation. Archives of sexual behavior, 1-7. 
Regnerus, M., Price, J., \& Gordon, D. (2017). Masturbation and partnered sex: substitutes or complements? Archives of Sexual Behavior, 46(7), 2111-2121

Robinson, J., \& Short, R. (1977). Changes in breast sensitivity at puberty, during the menstrual cycle, and at parturition. British Medical Journal, 1(6070), 1188-1191

Salmon, C., \& Fisher, M. L. (2018). Putting the "sex" into "sexuality": Understanding online pornography using an evolutionary framework. The Journal of the Evolutionary Studies Consortium, 9((Sp. Iss 2)), 1-15

Savin-Williams, R. C., Joyner, K., \& Rieger, G. (2012). Prevalence and stability of self-reported sexual orientation identity during young adulthood. Archives of sexual behavior, 41(1), 103-110

Shifren, J. L., Monz, B. U., Russo, P. A., Segreti, A., \& Johannes, C. B. (2008). Sexual problems and distress in United States women: Prevalence and correlates. Obstetrics \& Gynecology, 112(5), 970-978

Smuts, B. B., \& Smuts, R. W. (1993). Male aggression and sexual coercion of females in nonhuman primates and other mammals: Evidence and theoretical implications. Advances in the Study of Behavior, 22(22), 1-63

Tyson, G., Elkhatib, Y., Sastry, N., \& Uhlig, S. Are people really social in porn 2.0? In Ninth international AAAI conference on web and social media, 2015.

Whitehouse, H., Francois, P., Savage, P. E., Currie, T. E., Feeney, K. C., Cioni, E., et al. (2019). Complex societies precede moralizing gods throughout world history. Nature, 568(7751), 226-229

Woo, J. S., Brotto, L. A., \& Gorzalka, B. B. (2011). The role of sex guilt in the relationship between culture and women's sexual desire. Archives of Sexual Behavior, 40(2), 385-394

Yach, D., Stuckler, D., \& Brownell, K. D. (2006). Epidemiologic and economic consequences of the global epidemics of obesity and diabetes. Nature medicine, 12(1), 62

Yerkes, R. M., \& Elder, J. H. (1936). Oestrus, receptivity, and mating in chimpanzee. Johns Hopkins Press.

Publisher's Note Springer Nature remains neutral with regard to jurisdictional claims in published maps and institutional affiliations. 